\title{
PERSPECTIVAS E DILEMAS DA ENFERMAGEM NA PÓS-MODERNIDADE: DIALOGANDO COM ZYGMUNT BAUMAN
}

\section{PERSPECTIVES AND DILEMMAS OF NURSING IN POST-MODERNITY: DIALOGUE WITH ZYGMUNT BAUMAN}

\section{PERSPECTIVAS Y DILEMAS DE LA ENFERMERÍA EN LA POSMODERNIDAD: DIALOGANDO CON ZYGMUNT BAUMAN}

\author{
Antonio Jorge Silva Correa Júnior ${ }^{1}$, Raisa Silva Martins ${ }^{2}$, Mary Elizabeth de Santana ${ }^{3}$
}

\section{RESUMO}

Objetivo: refletir sobre temas cruciais do cuidar em saúde e da prática de enfermagem sob a lente do sociólogo Zygmunt Bauman e do paradigma pós-moderno descrito em suas obras. Método: estudo teórico-reflexivo baseado no fichamento de livros de autoria de Zygmunt Bauman, complementados com conclusões e formulações de outros estudos. Resultados: as temáticas examinadas foram o amor, amor-próprio, redes de apoio, desgaste dos laços humanos, atrição com sistemas de cuidado tradicionais, refugo humano, volatilidade das posições sociais, no mercado de trabalho e identidade. Seguindo uma linha de pensamento inteligível, foram desenvolvidas ao longo de três eixos de discussão: "Dilemas da fragilidade dos laços humanos e breves paralelismos com o cuidar em saúde"; "Antigo dilema líquido dos refugados e dos sistemas de cuidado: necessidade das teorias holísticas"; e "Regime de crise e dilemas na configuração teórico-sócio-identitária do trabalho de enfermagem". Conclusão: Bauman analisa extensivamente e com pessimismo a pós-modernidade, reafirmando-a como desgastada em diversos âmbitos. 0 cuidar de enfermagem encontra incalculáveis barreiras diante da desvalorização dos vínculos, decerto valorizar, resgatando teorias holísticas de enfermagem, são os mecanismos para lutar contra tal contexto, culminando em uma árdua, fundamental e permanente configuração teórico-sócio-identitária da enfermagem na pós-modernidade.

Descritores: Enfermagem Holística; Teoria de Enfermagem; Sociologia.

\begin{abstract}
Objective: to reflect on crucial topics on health care and nursing practice through the lens of the sociologist Zygmunt Bauman and the postmodern paradigm described in his works. Method: theoretical and reflective study based in highlights of the books authored by Zygmunt Bauman, supplemented with findings and formulations of other studies. Results: the examined themes were love, self-esteem, support networks, wear of human ties, discord with traditional care systems, human waste, volatility of social positions in the labor market and identity. Following a line of intelligible thought, they three axes of discussion were developed: "Dilemmas on fragility of human ties and brief parallelisms with health care", "Old liquid dilemma on human waste and care systems: need for holistic theories" and "Crisis regime and dilemmas on theoretical and socio-identity configuration of nursing". Conclusion: Bauman analyzes postmodernity extensively and with pessimism, reaffirming it as worn in different areas. Nursing care encounters incalculable barriers front of devaluation of the links. So, valuing, rescuing holistic theories of nursing, are the mechanisms to fight against this context, culminating in a tough, fundamental and permanent theoretical socio-identity configuration of nursing in postmodernity.
\end{abstract}

Descriptors: Holistic nursing; Nursing theory; Sociology.

\section{RESUMEN}

Objetivo: reflexionar sobre cuestiones cruciales en la atención em salud y la práctica de enfermería a través de la lente del sociólogo Zygmunt Bauman y el paradigma posmoderno que se describe en sus obras. Método: Estudio teórico reflexivo basado en informes de libros de Zygmunt Bauman, complementados con los resultados y las formulaciones de otros estudios. Resultados: Los temas examinados fueron el amor, la autoestima, las redes de apoyo, fugacidad de las relaciones humanas, la atrición con los sistemas tradicionales de atención, los desechos humanos, la volatilidad de las posiciones sociales en el mercado de trabajo y la identidad. Siguiendo una línea de pensamiento inteligible, que se desarrollaron a lo largo de tres ejes de discusión: "Los dilemas de la fragilidad de los vínculos humanos y breves paralelismos con el cuidado de la salud", "Viejo dilema líquido de los desechos humanos y los sistemas de atención: necesidad de las teorías holísticas" y "Crisis del régimen y dilemas en la configuración teórica y socio-identidad de la enfermeira". Conclusión: Bauman analiza en extensión y con pessimismo la posmodernidad, la reafirmando como erosionada en diferentes áreas. Los cuidados de enfermería sufren las barreras incalculables ante de la devaluación de los lazos, ciertamente el rescate de las teorías holísticas de enfermería, son mecanismos para luchar contra este contexto, culminando en uma configuración de identidad socio-teórico duro, fundamental y permanente de la enfermería en la posmodernidad. Descriptores: Enfermería holística; Teoría de enfermería; Sociología.

${ }^{1}$ Graduado em Enfermagem. Mestrando em Enfermagem pela Universidade Federal do Pará. ${ }^{2}$ Graduada em Enfermagem pela Universidade Federal do Pará. ${ }^{3}$ Graduada em Enfermagem. Pós-Doutora pela Escola de Enfermagem de Ribeirão Preto da Universidade de São Paulo. Professora Titular da Universidade do Estado do Pará; Professora Associado I da Universidade Federal do Pará. 


\section{INTRODUÇÃO}

Buscar pela saúde e/ou qualidade de vida na pós-modernidade permeia inúmeros desafios conceituais e práticos; a visão ambiental dicotômica de fatores autoproduzidos ligados ao consumo e modelos ocupacionais, fatores externos indomáveis e os pertinentes ao acesso dos serviços de saúde. Por conta disso, já é sabido que alguns estilos de vida e ecossistemas trazem efeitos mórbidos populacionais, e não obstante a clínica para determinadas patologias passa a requerer um aparato tecnológico, diagnóstico e terapêutico sobremodo elitizado e distante das camadas menos favorecidas ${ }^{(1)}$.

As críticas da Saúde Pública ao avanço da tecnociência na pós-modernidade são o desvio do foco nos coletivos humanos e seu remanejamento para coletivos socialmente excluídos, ao deixar de proceder neste recorte a saúde restringe-se e submete-se à impossibilidade de superação da pobreza. Outra crítica é endereçada às atividades pontuais de promoção à saúde e prevenção de agravos, com a disseminação das informações a este respeito são gerados e propagados ideários reducionistas de saúde e adoecimento. Modernamente, os desígnios pela mudança de estilo de vida são mercadologizados e estreitamente econômicos e, comumente, compreendidos pelos receptores como a forma de expandir a juventude e como o remédio para a morte ${ }^{(1)}$.

Enquadrado nisto, o cuidar é preliminar ao histórico da enfermagem, porém desde o Império Romano e da Idade Média já eram perceptíveis os papéis de mulheres cuidadoras, em especial na ocasião de auxílio àquelas que acabavam de dar à luz e seus filhos. Os hospitais surgem como entidades nas laterais de igrejas e catedrais, servindo e socorrendo a massa populacional mergulhada na miséria, fome e nas aterradoras epidemias que assolaram a Europa na Idade Média. Estes constituintes darão à saúde, à doença e às deficiências fortes componentes mágico-religiosos ligados à razão supersticiosa da época ${ }^{(2)}$.

Sujeita aos modelos, a enfermagem experimentou $\mathrm{o}$ paradigma científico antes vigente que privilegiava a resposta objetiva dos fenômenos erguidos diante dos homens, o positivismo consolidado como fonte de rigor científico, racionalidade e quantificação.
Entretanto, somente foi exequível a superação deste paradigma no tocante à enfermagem, quando ocorreram as buscas de novas taxonomias como as orientadas pela Associação Norte Americana de Enfermagem (NANDA) e a Sistematização da Assistência de Enfermagem $(\mathrm{SAE})^{(3)}$.

Vale frisar que o ponto de partida que adequadamente contextua a pós-modernidade é difícil por tratar-se da era das indeterminações, as sucessivas modificações quebrarão paradigmas e o homem confrontar-se-á constantemente com o salto de mundos simples para outros descomedidamente complexos. Neste momento, a sapiência alardeada como medular capta racionalmente apenas parte da realidade, o homem se vê fragmentado e emaranhado, os intercâmbios serviram a saúde e tornaram-na receptiva aos demais sistemas, como também geraram uma contingência que impulsiona a criação de novos sistemas e subsistemas ${ }^{(4)}$.

A conjuntura política global da contemporaneidade, marcada por crises, encontra em novos meios de sobrevivência concedidos pelo progresso tecnológico um grave problema: a degradação crescente das possibilidades de sustento das populações. $O$ crescimento econômico outrora benéfico agora sintetiza contingentes populacionais excessivos à lógica da modernização e de igual maneira precisam de amparo ${ }^{(5)}$. Contamos que novos paradigmas já foram e serão criados (como os da pós-modernidade), fundando novos dilemas éticos, morais e epistemológicos; a enfermagem por coabitar na vanguarda das mudanças da imaterialidade do cuidar precisa estar a par e refletir sobre estratégias de incorporação ou relegação de valores.

Para os enfermeiros é indispensável meditar sobre estes fenômenos (materiais e imateriais) do campo social e de trabalho, descortinando-os não como processos pontuais e residuais, e sim como originários de processos ininterruptos e globais. Ante isto, ponderando o vislumbre de inserção dos profissionais de enfermagem na pós-modernidade e delimitando dilemas de natureza "ético-social-filosófica" presentes na contemporaneidade, objetiva-se com este estudo ligar e refletir sobre amor, desamor, corrosão dos vínculos, crise e 
identidade, associados à profissão. A fundamentação que guia as linhas desta reflexão encontra-se em obras de Zygmunt Bauman.

\section{MÉTODO}

Trata-se de um estudo de cunho teóricoreflexivo enleado a aclarações críticas e conceituais alicerçadas, maiormente, sobre a obra do sociólogo Zygmunt Bauman e sua modernidade líquida, críticas à pós-modernidade, esgotamento do futuro e ao encurtamento dos vínculos sociais. Bauman é polonês, galardoado com prêmios de ênfase nas Ciências Sociais e Sociologia, com dezenas de livros traduzidos para o português e publicados no país ${ }^{(6)}$.

Um pequeno inventário de livros de sua autoria foi realizado, leituras flutuantes e a técnica do fichamento moldaram perspectivas de adição de elementos da saúde e da enfermagem. Finalmente, os livros que possuíram fragmentos consultados foram: "Amor líquido: sobre a fragilidade dos laços humanos"; "O mal-estar da pós-modernidade"; "Modernidade e ambivalência"; "Identidade" e "Vidas desperdiçadas". À luz de outros teóricos e autores com outras argumentações e experiências foram elencadas de forma complementar e cabível, exigindo assim uma linha indutiva.

\section{RESULTADOS E DISCUSSÃO}

Copiosos temas e conceitos sobre a tônica da pós-modernidade foram observados durante a leitura: amor, desamor, corrosão dos vínculos, individualismo, dificuldade em lidar com o outro, refugo humano, crise, mercado de trabalho e identidade, sendo agrupados em três eixos nos quais foram traçadas as reflexões.

\section{Dilemas da fragilidade dos laços humanos e breves paralelismos com o cuidar em saúde}

O cuidar é nobrificado por Bauman ao destacar o sujeito que ama como aquele a serviço do objeto ou ente amado, socialmente e politicamente responsabiliza-se, arca com a renúncia e imaterialmente com os gestos de amor se corporifica, paulatinamente, no mundo. Imputa-se a este sentimento tão inextrincável com as relações de poder: "O amor, por outro lado, é a vontade de cuidar, e de preservar o objeto cuidado. [...] Ingerir, absorver e assimilar o sujeito no objeto, e não vice-versa, como no caso do desejo (p. 24)"(7).
Desdobrado, o amor não é simplesmente um sentimento romantizado: é um comportamento sobressaído do respeito, da gentileza e da honestidade. O cuidar desenvolve os seres e quando executado na saúde difere na aplicabilidade, ao entender-se que a profissionalização da capacidade humana de cuidar (a enfermagem) prova seu amor no cuidado através da consolidação de técnicas, conhecimentos e habilidades. Por conta disto enfermeiras teorizadoras já diferiram cuidado genérico do cuidado profissional, bem como ciência de humanismo no meio acadêmico ${ }^{(8)}$.

Entende-se, assim, que a manutenção dos rituais e das ordens que reafirmam a identidade humana somente é possível por meio da consubstanciação social do preceito do amor ao próximo. Assegurado isto, pode-se facilmente contrapor as importâncias sociais do princípio do amor ao próximo e do amor-próprio: enquanto o último está relacionado à sobrevivência, o primeiro é o elemento concludente e desafiador da natureza que possibilita a existência humana de uma forma particular, destoando-nos de outros espécimes animais ${ }^{(7)}$.

O amor-próprio tramita paralelamente ao senso de sobrevivência, entretanto não é o componente indispensável para a conservação de nossas existências corporais. Os animais não o possuem e, contudo, salvaguardam-se instintivamente. Tais divagações sobre o amor fazem-nos outorgar o ideal de que até mesmo o amor-próprio é um desdobramento humano da esperança de ser notado na multidão por intermédio do reconhecimento de outrem. Completa-se esta questão com: "Em suma: para termos amor-próprio, precisamos ser amados. A recusa do amor - a negação do status de objeto digno do amor - alimenta a autoaversão. [...] Outros devem nos amar primeiro para que comecemos a amar a nós mesmos (p. 100)"(7).

Desemboca-se a partir dos pressupostos envolvendo o amor e amor-próprio, em achados interessantes sobre humanização no campus da saúde. Na percepção de enfermeiras de unidade de terapia intensiva, dar valor a si mesmo e ao outro são posturas que municiam a humanização; a comunicação com a equipe e com a instituição são elementos que engendram este processo, bem como a carência de valorização em relação ao serviço prestado e individualismo são fatores fortificadores do desenvolvimento de relações dificultosas entre os profissionais ${ }^{(9)}$. 
A necessidade de reconhecimento e apoio patente na realidade humana encontra na enfermagem um alento. Por exemplo, as figuras dos cuidadores familiares demandarão mais préstimos ao passo que durante seus itinerários encontrarem falta de apoio e cobranças na rede de relações informais. Na atenção ao núcleo familiar em situações análogas, a assistência deve estimular o autocuidado dos envolvidos, sendo significativo prevenir o adoecer daqueles que cuidam $^{(10)}$. Semelhantemente, a enfermagem aflora no relacionamento com cuidadores de sujeitos acometidos por esquizofrenia a melhoria no cotidiano de cuidados. Barreiras ainda são encontradas pela demasiada importância ao repasse de informações, em detrimento da atenção a outros aspectos do núcleo familiar e o imaginário social sobre como lidar com transtornos mentais ${ }^{(11)}$.

De acordo com recente revisão sistemática, as redes de apoio aparecem como relevantes para consumidores de álcool e drogas. Contribuem sobremaneira para melhora do tratamento e vida dos sujeitos; os laços profissionais, familiares e comunitários são cruciais na aquisição do suporte social, sem despojarem-se do trabalho profissionalizado as redes sociais dão uma perspectiva ampliada de saúde ${ }^{(12)}$. É através do atendimento que a ciência do cuidar avista as alternativas de desenvolvimento de ferramentas do outro para cuidar de si mesmo dentro de suas capacidades. $\mathrm{Na}$ solicitude, enfermeiras obstétricas cumprem seus papéis com paciência e tolerância propiciando às futuras mães encontrarem no decorrer da gestação suas potencialidades e ensejando que por meio de seus cuidados as mulheres tornem-se livres para si e para o filho durante o nascer ${ }^{(13)}$.

Então, em equivalência à indispensabilidade do aludido, julga-se que o fortalecimento deste ideal é decerto o que alguns procuram e/ou evitam na saúde: "Investir fortes sentimentos na parceria e fazer um voto de fidelidade significa aceitar um risco enorme: isso o torna dependente de seu parceiro [...] (p. $112)^{\prime \prime(7)}$. A temerosidade em aproximar-se demais (não apenas de parceiros amorosos) e criar vínculos infiltra-se nas mentalidades dos trabalhadores dos quais se exigem envolvimento psicológico e emocional, contudo, para combater esta ideologia, presume-se: "embora devamos observar que esta dependência, que agora está se tornando rapidamente um termo pejorativo, é aquilo que consiste a responsabilidade moral pelo Outro [...] (p. 112)"(7).

Sem negligenciar 0 suscitado, o autocuidado defendido pela enfermagem possui um caráter político, uma vez que estas práticas permitiram no passar da história o aparecimento de diversas subjetividades ${ }^{(14)}$. Todavia, será possível (re)inventar formas de cuidar que emancipem os indivíduos na pós-modernidade? A garantia do amor e do amor-próprio se vê vigorosamente tão necessária quanto abalada nesta conjuntura.

Infelizmente, ao debruçar-se sobre a maneira com a qual enxerga-se o outro através da lente do mundo pós-moderno, verificamos a fundação de um ideal separatista e competitivo. Ser áspero, não possuir remorsos, fortes escrúpulos e manter-se vigilante e desconfiado garante que nenhum dos outros atores sociais possa nos confundir ou enganar e, portanto, a sequela produzida a nível relacional é a mitigação de compromissos duradouros ou incondicionais. A exceção aberta sobre os outros, os estranhos, segundo Bauman, é: "Aproximar-se, colocar-se ombro a ombro e trabalhar em equipe fazem muito sentido enquanto ajudam a avançar em caminho próprio (p. 110)"(7).

Para estabelecer a relação de quando alguma aproximação é benéfica apenas unilateralmente, pode-se dissertar sobre a maneira com a qual os profissionais têm promovido suas carreiras na saúde através do cybermarketing no Facebook (rede social criada em 2004). A evidenciação indevida das condições dos pacientes por meio de imagens postadas assume, em meio a crescente popularização do registro de atividades laborais, contornos comprometedores quando ferem os princípios éticos de privacidade e confidencialidade. Muito embora, quando corretamente realizados nas redes virtuais, são capazes de serem empregados para o devido esclarecimento dos sujeitos ${ }^{(15)}$.

Nas ocasiões em que imagens das condições físicas e nomes dos pacientes são expostos e disparados no ciberespaço, podem ser acessadas por usuários leigos que as remetam a estereótipos ou emitam observações aviltantes. Tal questão nos impele a pensar nas motivações dos profissionais cientes dos danos decorrentes de suas ações ${ }^{(15)}$. As imagens não devem ser coisificadas, e sim relativizadas, tanto com relação à dimensão crítica de seus 
receptores (os valores, opiniões e experiências do grupo) quanto com relação ao contexto circunscrito ao registro ${ }^{(16)}$.

É digno de nota que com a ruptura de vínculos duradouros, de laços com a família, cidade e com as múltiplas formas de solidariedade e da sensibilidade passa a existir uma lacuna entre o indivíduo e a esfera social maior - antes o intermédio era realizado por estas instituições sociais, agora renegadas ao segundo plano, logo a televisão, internet e "redes" ocupam espaço como condutoras de informação dos indivíduos para o todo no qual residem. Entretanto, aquilo que estrutura o agir sensível é abandonado nestas ferramentas de conexão, pautadas na valorização da modernidade e do indivíduo e, paradoxalmente, de uma economia de mercado igualitária, todos se veem atualmente em uma grande sociedade individualista de massa ${ }^{(16)}$.

Os valores contemporâneos transmitem o declínio do ideal de ligação da vida a alguma vocação e a abstenção de coerências. Na Era líquida, há uma particular aversão à durabilidade e recusa à fixação, trazendo à tona uma preocupante e perpétua peregrinação por ocasiões novas, que deem à vida um status quo de jogo demasiadamente curto. Para Bauman, esta analogia se deve às repentinas mudanças no curso das vidas dos pós-modernos, sucedidas perante regras que a qualquer momento podem desintegrar-se e reinventarem o jogo ${ }^{(17)}$.

Em decorrência da rapidez com a qual trocas se dão no jogo pós-moderno, a descartabilidade dos seres humanos é validada enquanto modus operandi, exprimindo que cada um de nós está por conta própria na vida em sociedade. A crueldade desta circunstância transfigura-se em desestimação dos méritos adquiridos e na eventual exclusão que os jogadores efetuam uns contra os outros a fim de galgarem o sucesso, admitindo cooperações apenas quando forem em vantagem própria ${ }^{(7)}$.

Em passagens de "Vidas Desperdiçadas" é incorporado mais um fator ao jogo pós-moderno, a sociedade de produtores consegue obter vantagens da legião de desempregados, afinal encorpam unidades de reserva de mão de obra, entretanto nenhuma serventia pode ser extraída dos consumidores falhos em uma sociedade consumista. Devido à privação da qualidade de consumidor atuante, muitos perdem automaticamente a posição de jogadores do único jogo disponível sendo descartados da lógica mercadológica ${ }^{(5)}$.

Esta fragilidade dos vínculos corrobora com a tese de que os tempos líquidos podem ser relacionados aos dilemas da saúde traçados aqui (e discorridos também em posteriores eixos de discussão), desencadeadores da vaidade profissional, quando está intimamente ligada ao desmantelamento do amor e do descomprometimento com a sua categoria profissional em casos extremos.

Agora, desde os conceitos-chave do que é o amor, no que consiste a corrosão dos vínculos humanos e a operacionalização dos jogos pósmodernos: que contribuições podem ser captadas pelo enfermeiro? A saída também se encontra em "Amor líquido: sobre a fragilidade dos laços humanos": "Amar o próximo como amamos a nós mesmos significaria então respeitar a singularidade de cada um - o valor de nossas diferenças que enriquecem $o$ mundo que habitamos em conjunto [...] (p. 101)"(7).

Novamente em réplica, há de se considerar o exercício do enfermeiro habituado a processos tradicionalísticos mecanizados, fragmentados e disciplinantes. Essa racionalidade técnicoinstrumental e curativa saturada despertou a própria superação para dar lugar a fundamentos epistemológicos que embasassem seu potencial reflexivo por intervenção preferencialmente da reflexão-na-ação ${ }^{(18)}$. Em suma, exteriormente, é vital enxergar as dimensões do outro, encarnando uma postura ampliada de assistência e admitindo que a propiciação de subjetividades do outro seja fundamental para combater a trivialização da existência humana ${ }^{(19)}$.

\section{Antigo dilema líquido dos refugados e dos sistemas de cuidado: necessidade das teorias holísticas}

As incertezas no âmbito da atenção à saúde na Era líquida não derivam unicamente do viés relacional, atravancado pela mitigação do amor e da responsabilidade por outrem. A desigualdade social é crucial ao considerar-se a formação de massas de pessoas "excessivas", "redundantes", inaptas, deslocadas e indesejáveis na estrutura moderna - o refugo humano. 0 planeta tramita atualmente entre um frágil equilíbrio das forças sociais, apogeu na produção de pessoas refugadas, a crise em espaços aptos que acolham estes indivíduos e a deterioração da segurança, com tal intensidade tais dilemas agregam-se à cultura da individualização ${ }^{(5)}$. 
É substancial mencionar o refugo humano, uma vez destituído de meios de subsistência e declarado majoritariamente uma obrigação do Estado carecendo de alimento, roupas, abrigo e, por conseguinte, gerando ônus financeiro. Os indesejáveis da modernização se veem presos à permanência de suas sobrevivências em uma pósmodernidade pensada para ser desigual e que de modo algum vai reinseri-los ${ }^{(5)}$.

Concatenar os refugados e ponderações em saúde é admitir que as problemáticas trazidas pelos clientes com baixo poder aquisitivo, geralmente, são de cunho socioeconômico e político, podendo ser resolvidas (integralmente) por instâncias superiores: "Agora se veem em face da necessidade de procurar (em vão, ao que parece) soluções locais para problemas produzidos globalmente (p. 13)"(5). Nisto então, reside o grande dilema da saúde atualmente?

Contumazes são os problemas de cunho social na saúde, então vale pensar nos pilares do atual modelo em que os usuários geralmente são cooptados como protagonistas ao optarem e utilizarem "modelos de escolha" individual, no contexto dos sistemas de cuidado. Porém, há de se observar mundialmente a força que o discurso neoliberal ganhou com health care choice $\mathrm{e}$ perante os usuários e, ainda sim, atentar-se para complexidades socioculturais não inerentes à política no âmbito da escolha para cuidados em saúde ${ }^{(20)}$.

A cultura dominante quando representada por médicos, psicólogos ou psicanalistas, por exemplo, encontra barreiras ligadas à incompreensão de indivíduos de classes subjugadas ou percebidas como subculturas. Decerto, o saber oficial instituído pela ciência e seus profissionais sempre encontrou na observação das patologias um paradoxo: "suas referências, seus padrões de normalidade, sua avaliação de trajetórias e bem-estar pessoal estão inseridos em uma visão de mundo comprometida com certas ideias de eficiência, produtividade, associadas ao que se denomina individualismo burguês [...] (p. 32)"(21).

As discrepâncias entre os juízos de valores estabelecidos pelo saber biomédico e a prática em saúde são observadas in loco. Dão-se frequentemente por intermédio do choque com o saber dos provedores de cuidados, que exercem competências "médicas" e terapêuticas, depreendendo cuidados em saúde assentados na subjetividade, socialização e experienciação da tradição. Tais sistemas etnomédicos foram identificados em Moçambique, relativos às cosmovisões, diferentes nomenclaturas da doença e grupos de provedores de cuidado aos quais os adoecidos pela malária recorriam em primeira instância, todo o processo de padecimento é entrecortado por narrativas em que a gama de aspectos socioeconômicos e ambientais é privilegiada ${ }^{(22)}$.

É interessante notar em casos como do distrito de Chókwè em Moçambique que o saber instituído pelo modelo biomédico penetra o léxico e os diagnósticos locais, não obstante, reconfigura a rede de cuidados e sobrepõem-se aos provedores tradicionais nas políticas de saúde. O reconhecimento da malária realizado pelos saberes e terapias locais vai ajustando-se às novas terminologias introduzidas e torna-se intricado devido aos sintomas de outras etnodoenças também enfrentadas ${ }^{(22)}$.

Na conjuntura brasileira, a Saúde Coletiva tornou-se o preâmbulo do encontro das ciências humanas e sociais com as da saúde, exercendo a respeitável atribuição de produzir conhecimento e pôr em prática políticas públicas. Mais recentemente, uma nova equação passou a ser debatida: o biológico (antes encarado como imutável) pode transmutar-se em articulação com o meio sociocultural, ademais, a cultura só pode ser contextualizada na existência biológica. De nenhuma forma podem dissociar-se. Outrossim, não são as ciências sociais enquanto movimento acadêmico que tornaram urgente suas aproximações, e sim a sociedade organizada com destaque para o feminismo, movimento de Gays, Lésbicas, Bissexuais e Transexuais e a Reforma Psiquiátrica por exemplo, que conclamaram a participação dos sujeitos no acesso à saúde ${ }^{(23)}$.

Haja vista toda esta complexidade sociocultural, o cuidado às perturbações orgânicas e psicológicas é depreendido de forma dificultosa pelos trabalhadores da saúde. No âmbito brasileiro este embaraço revela-se nas interações, nas quais a cultura dominante continuadamente qualificará com atributos exóticos e rótulos depreciativos os sistemas de cuidado provenientes de camadas de menor renda. A discordância surge no fazer profissional, derivando da simplificação racionalista incutida no ideário da saúde e a falta de relativização contextual em relação às problemáticas trazidas pelo usuário ${ }^{(21)}$.

Os estudos sobre o cuidado, percepções, vivências e sentimentos dos adoecidos e comunidades são basilares na enfermagem, 
desde muito geram implicações filosóficas, educacionais, administrativas e ritualísticas na vida dos estudados e dos que consomem essa literatura. Do mesmo jeito, trazem a evolução e postulação de métodos de pesquisa qualitativa, como a etnoenfermagem ${ }^{(8)}$. Através das problemáticas subjetivas trazidas pelos adoecidos na pós-modernidade, resta-nos traçar os reflexos para a enfermagem a partir destas procuras por identidades contemporâneas (nossas e deles) e conectá-las com os padrões assistenciais a serem seguidos como especialistas do cuidar. Doravante, como afastar-se de um ideal não humano de trabalho permanece como uma indagação cabível aos enfermeiros.

Regressando às reflexões primeiramente traçadas, uma justificativa emergente para a despreocupação dos mais abastados com as condições sociais - opostas e adjacentes - é a falta da noção de pertencimento ao local ou cidade que habitam, já que frequentemente suas inquietações e responsabilidades flutuam longe destes espaços. Munidos de conforto, com serviços e lazeres devidamente assegurados, esta população urbana perfeitamente situada não possui estima pela sua localidade ao contrário das camadas menos validas essencialmente locais e carregadas de (des)esperança e sonhos ${ }^{(7)}$.

As metáforas baumanianas chamam este processo de "hiato entre os espaços vivos/vividos [...] comprovadamente o mais seminal de todos os afastamentos sociais, culturais e políticos ( $p$. $121)^{\prime \prime(7)}$. Neste caso, apesar de potenciais conflitos abordados no decorrer desta reflexão, a enfermagem desfruta de um baluarte de teorias, métodos de pesquisa e determinações técnicas e éticas que certamente proporcionam um resgate da sensibilidade em meio aos dilemas e à dissipação dos vínculos nas cidades.

A teoria de déficit do Autocuidado de Orem e a Teoria do Cuidado Transcultural de Madeleine Leininger apresentam aplicabilidade e atrelam-se às ponderações sobre amor, humanização e integralidade. Destarte, o cuidado transcultural é levado em consideração enquanto estratégia de atenção integral por perceber os fenômenos partícipes da realidade e as dinâmicas das vidas dos sujeitos, quando aplicado à clínica beneficia não apenas indivíduos de culturas longínquas em relação ao profissional, como também populações vulneráveis e marginalizadas ${ }^{(24)}$.

Ao considerar-se a vivência histórica de marginalização, vulnerabilidade e discriminação dos migrantes, os cuidados culturalmente congruentes levam a uma atenuação de barreias clínicas usando dinâmicas que propiciam o bemestar e a saúde. Muitos destes trabalhadores itinerantes de backstretch apresentavam maior suscetibilidade a agravos de saúde e ao receberem serviços de enfermagem sob o modelo transcultural puderam superar obstáculos no acesso $^{(24)}$.

Por sua vez, o autocuidado tem como sustentáculos a Teoria de autocuidado, Déficit de autocuidado, e o Sistema de enfermagem preconiza a partir de um déficit identificável a produção de assistência do enfermeiro. Interpreta-se o ato de estar no mundo e metamorfosear-se como espécies de exercício político, integrantes da proposta de cuidar de si mesmo ${ }^{(14)}$. O "ser atendida" e o "ser ouvida" instigaram o estímulo ao autocuidado de gestantes usuárias de crack em unidade de desintoxicação química. Neste sentido, as atividades e $o$ cuidado de enfermagem melhoraram a estima das usuárias e despertaram o desejo pela conquista da felicidade ao lado de seus filhos sem o entorpecente ${ }^{(25)}$.

Similarmente, na promoção de ações educativas à clientela com sofrimento psíquico, a enfermagem almeja resgatar a motivação para o cuidado de si existente nos usuários, ambicionando o aperfeiçoamento quanto à autoimagem e interação destes, vivências narradas em projeto de extensão em Centro de Atividades Terapêuticas ${ }^{(26)}$. As ações de autocuidado são intencionais e praticadas mediante o intento de manter-se íntegro para a vida social, suas condições determinantes são socioculturais, ambientais, familiares, além de correspondentes à individualidade de cada pessoa $^{(14)}$.

Em "Dilemas da fragilidade dos laços humanos e breves paralelismos com o cuidar em saúde", foi emitido um questionamento sobre a viabilidade em (re)inventar formas de cuidar emancipadoras dos indivíduos na pósmodernidade. Julga-se que as ações em Orem e Leininger ajustam-se à precisão de não perder as identidades assistenciais holísticas e éticas, devese crer que são necessárias perante a modernidade líquida que desestima e esvazia a existência social humana, nossos cernes de trabalho.

Nada é estático e o processo de trabalho é alterado continuamente com os avanços do pensar e agir, ante isto a saúde e a enfermagem agregaram ao cuidado holístico novas 
epistemes $^{(3)}$. Até mesmo as costumeiras explicações literárias da enfermagem, como assentada na arte cognitiva e no raciocínio lógico amplamente qualificado e científico, parecem insuficientes, já que regularmente decisões são tomadas em esferas de conhecimento destacadas e que não admitem cooperação. Impreterivelmente, as práticas de enfermagem devem possuir um significado muito mais de "teoria na prática" do que no racionalismo extremo ${ }^{(27)}$.

Baseados no dialogismo da "Teoria da prática" de Pierre Bourdieu em momentos matutinos de uma enfermaria, em artigo recente, percebeu-se que o sentido das ações de enfermeiros através da lente de Bourdieu, são basicamente os de jogadores em uma partida, organizando médicos, pacientes e gerenciando o desenrolar do trabalho diário em um contexto limitado, por vezes ${ }^{(27)}$. Colaborando com a questão do racionalismo exacerbado, a dificuldade em enxergar a realidade dos pacientes e acercar-se do locus no qual trabalha é um dos dilemas das profissões da saúde, ainda sim, a identidade da categoria de enfermagem deve estar fixada na contramão de modelos excludentes.

\section{Regime de crise e dilemas na configuração teórico-sócio-identitária do trabalho de enfermagem}

A intitulada "Geração X" padece por observar a volatilidade das posições sociais, redução de perspectivas da própria qualidade de vida e a impossibilidade de colocações duradouras. A educação superior tornou-se o mais ínfimo parâmetro para a vida digna, apenas por afigurar-se em uma minoria privilegiada. Bauman salienta estas disparidades com uma jocosa exemplificação: "O mundo, ao que parece, deu outro giro, e um número ainda maior de seus habitantes, incapazes de aguentar a velocidade, caiu do veículo em aceleração - enquanto um contingente maior dos que ainda não embarcaram não conseguiu nem mesmo correr [...] (p. 23)"(5).

Este regime de crise no qual os sujeitos da Geração X estão enredados é produto da ingênua sensação de que a felicidade comporta muitos "passageiros", quando na verdade há a imposição de cada vez menos indivíduos nas guinadas da modernidade. Muitos ficam para trás, abandonados ou engolidos, analogamente, a criteriosidade e superlotação do mercado de trabalho e a depressão massiva são produtos desta era de incertezas, acarretando um sentimento de desagregação existencial nunca visto de forma tão contundente em nossos antepassados, quando imperavam problemas diferentes dos da contemporaneidade ${ }^{(5)}$. Diante do prosseguimento na produção dos refugados, da perda da sensibilidade e de fixação no mercado de trabalho, os trabalhadores da saúde devem (dificultosamente) ser impelidos à formulação de estratégias de reformulação ou resgate de suas identidades assistenciais.

Segundo passagem de "Identidade", a perda de unidade das categorias deve-se a um mercado de trabalho globalizado em que todos se esforçam para serem notados pelos seus chefes, e não há espaço para a solidariedade proletária $^{(28)}$. Em síntese, está associada ao alto grau de competitividade e desconfiança, explícitos nos jogos pós-modernos, como na dificuldade dos sujeitos em construírem identidades lineares, perenes e compromissadas com alguma conviç̧ão. O grande dilema contemporâneo não é descobrir, inventar ou delinear qualquer identificação, é na verdade impossibilitá-la de aderir a sua existência física, vista como essencialmente inconstante ${ }^{(17)}$.

Adstrito ao supracitado, o especialista não é notável pelos seus predicados acadêmicos ou posses, e sim como é percebido pelos seus receptores e pela variedade de problemas escutados, evidenciando a personificação da individualidade dos seus requisitantes. Por outro lado, os clientes que buscam especialistas objetivando traduzir suas necessidades (frequentemente subjetivas) em parâmetros confiáveis, imparciais e técnicos firmam suas autonomias através da submissão segundo o sociólogo ${ }^{(29)}$.

Fazendo uma analogia breve com serviços computadorizados, para os clientes o importante é a confiança na função interpretativa do especialista, e não sua humanidade. Procurar especialistas localiza-se no paradoxo pósmoderno da identidade individual que deve ser alcançada a qualquer custo, para nós e clientes: carecemos de uma diferença estável em relação ao outro e ao mundo e ainda sim precisamos de aprovação social, logo usuários creem na especialização quando incertezas pessoais se tornam problemas interpessoais e pedem resolução. Todos estes "problemas individuais" na atenção especializada possuem tabulações 
socialmente aceitas e replicadas ${ }^{(29)}$, portanto decifrar esta questão é crucial para saúde.

Acima se citou a perda de identidade durável e aderida a existência física, sob a ótica pessimista baumaniana, contudo o autor assente: "A identidade durável e bem costurada já é uma vantagem; crescentemente, e de maneira cada vez mais clara, ela se torna uma responsabilidade (p. 114)"(17). Então, presumivelmente, devemos configurar de maneira firme nossas identidades dificultosamente ou não, levando em conta o arcabouço de teorias holísticas, os sistemas de cuidado, a particularidade dos clientes e os meandros da Era líquida.

Elaborar este perfil é possível mediante transformações curriculares que permeiem as possibilidades do acadêmico que ingressará no mercado. Sobre a identidade de enfermeiros docentes e pesquisadores é sublinhada a importância do estudo associado à práxis, aliada ao ímpeto de criar e divulgar novos conhecimentos enquanto constituintes da profissão. A atual identificação pessoal dos sujeitos enfermeiros - situada entre a docência e a pesquisa - gera atribuições únicas ao referido papel: as de amplificar e conceber novas teorias e formas de cuidar dos clientes ${ }^{(30)}$.

Conforme o estrato teórico em que o cuidado se centraliza, finalmente, pode-se cruzar outra seara de impasses ligados ao estresse, sofrimento e à insatisfação laboral que rotineiramente entram em confronto com a paciência exigida pela saúde. Perante as crises humanas exemplificadas dentro da pósmodernidade, como tais perturbações extrínsecas e intrínsecas ao trabalho podem afetar a configuração identitária do enfermeiro?

Dados de estudo com trabalhadores de Atenção Básica, em 15 unidades de município do Rio Grande do Sul, corroboram para avaliações impróprias das condições de trabalho. É particularmente relevante ressaltar as estratégias de enfrentamento formuladas pelos trabalhadores mais antigos, em relação ao combate ao sofrimento laboral, haja vista o menor esgotamento profissional e menor liberdade de expressão que os mesmos possuem em comparação aos trabalhadores mais jovens, até então supridos por grandes expectativas quanto às suas funções, as quais podem ser corroídas caso não sejam cumpridas ${ }^{(31)}$.

Segundo revisão integrativa recente apontou, a qualidade de vida dos enfermeiros ativos em serviços hospitalares sofre máculas advindas da estrutura onde se enquadrou, as duplas jornadas de trabalho, acidentes laborais, sobrecarga, restrição de pessoal e material, carência de reconhecimentos e plantões noturnos ${ }^{(32)}$.

Outra inspeção bibliográfica detectou a não existência de atuação comprometida em locais cujos profissionais encontram-se estressados, também inexistem estudos recentes que descrevam com exatidão o que é mais estressante. Consequentemente, acresce agentes estressores severos ao exercício de enfermagem, como a exigência de assistência mais acurada a pacientes graves, carência de qualificação e alta requisição dos sujeitos ${ }^{(33)}$. Em contrapartida, os coeficientes harmoniosos para satisfação no labor estão relacionados às horas de trabalho, remuneração, equipe, autonomia e alcançar os resultados esperados com os cuidados ${ }^{(34)}$.

Penetrar na questão é conjecturar que caos instaurado na configuração de identidades (profissionais ou não) na Era Líquida está relacionado ao colapso do bem-estar social, à flexibilidade do trabalho, privatização da esfera pública e à corrosão do caráter. A identidade dos trabalhadores se vê abalada nesta conjuntura na qual não pode ser eterna, sendo uma ideia particularmente ambígua e conectada ao campo das batalhas quando reivindicada por grupos em relação a algum ego coletivo, porém, no presente ínterim, prolonga-se entre a interminável construção e dissolução ${ }^{(28)}$.

\section{CONCLUSÃO}

Seguindo a exploração perpetrada em Bauman, refletiu-se sobre a ligação do amor ao próximo e amor- próprio com o agir do enfermeiro; degradação das relações humanas; efeitos deletérios dos jogos pós-modernos; necessária assistência ao refugo humano e a observância de seus sistemas de cuidado; e a difícil configuração teórico-sócio-identitária dentro da saúde na pós-modernidade entrecruzada pela volatilidade de posições, impasses no mercado de trabalho mundial, especialização da assistência, estresse e insatisfação laboral.

Enfatizam-se as limitações da formulação ao não abordar ostensivamente a globalização, mercantilização da saúde e as ferramentas digitais e seus reflexos, apesar da extensa literatura do pensador sobre. Ao eleger as temáticas primeiramente citadas para reflexão, observamos o ceticismo quanto aos vínculos 
humanos pós-modernos encobertos pelo esgotamento, relações humanas desagradáveis, porosas e curtas. A ótica pessimista de Bauman e as afirmações contidas em suas obras derivam de processos e análises abrangentes, não possuem uma direção, e sim "direções", provavelmente no campo da saúde não podem ser levadas em consideração particularmente, e sim universalmente.

Durante o primeiro eixo, interpretamos o contexto pós-moderno de amor e desamor, bem como suas tênues ligações com o universo de enfermeiros e clientes. Para encorajá-los a encontrarem o amor-próprio e ferramentas de autocuidado, precisamos primeiramente fortalecer nossas convicções humanas para então avigorar suas redes de apoio pela flexibilidade e respeito de nossas condutas. 0 medo de entregar-se a algum paciente e a vaidade profissional brevemente explanada podem ser um desdobramento da fragilização dos vínculos, teceram-se, assim, considerações de o quão perniciosa é a macroestrutura dos jogos pósmodernos nas condutas da saúde.

Especialmente, sabendo que a enfermagem deve afastar-se do ideal não humano de trabalho e da perda de vínculos de empatia, confiança e reciprocidade, traçamos contribuições para o segundo eixo. Vale frisar que outros dilemas foram lançados, como a produção de refugados, a distância erguida imaterialmente dentro das cidades entre os profissionais e seus usuários e sistemas de cuidado. Porém, para tratar as experiências de vulnerabilidade, invisibilidade e dificuldade de autocuidado, ponderamos que as teorias holísticas de enfermagem - Cuidado Transcultural e Teoria do Déficit de Autocuidado aqui pareadas - permitem enxergar o outro de forma integral. Devem ser aplicadas ao processo de trabalho a fim de pugnar os descritos e valorizar os sistemas de cuidado que a profissão delimitou.

Pensa-se no determinante para uma remodelagem - o resgate dos valores fundamentais deve ser obtido pela fixação de uma identidade linear, comprometida com a profissão e longe da cultura no individualismo e dos discursos vazios avolumados pelas vicissitudes e dilemas de cunho ético, moral e prático nas vidas dos trabalhadores da enfermagem. Dentre estes, certamente, esbarram-se a pesada carga laboral e as incertezas do mercado de trabalho e da especialização assistencial, abordadas aqui superficialmente no terceiro eixo.

É reconhecido pelo autor que tais fatores deletérios da pós-modernidade são decisivos para a configuração de identidades, além de afirmar que apenas soluções globais podem ser efetivas, todavia muitas das problemáticas precisam ser revertidas para o curriculum das graduações, especificamente pelos docentes de enfermagem com foco socioassistencial.

Em suma, tomando como referência o suporte conceitual desta miscelânea de obras de Bauman e demais autores, respaldamos a impossibilidade de amar a distância ou por meio do ensino de técnicas, tais projetos apenas engrossariam o jogo da fragilidade dos vínculos. Novas teorizações e reflexões devem ser traçadas em relação à enfermagem - ainda em Bauman, mas elucida-se o papel de facilitadora do processo de cuidar que se vê abalado pela atual conjuntura, confundindo a configuração teóricosócio-identitária da enfermagem na pósmodernidade com o necessário resgate, avivamento e remodelagem de formas (teóricas ou não) de pensar no amor por outrem.

\section{REFERENCES}

1. Carvalho Al. Da saúde pública às políticas saudáveis: saúde e cidadania na pósmodernidade. Cienc Saúde Coletiva. 1996;1(1):104-21. https://doi.org/10.1590/1413812319961101572014

2. Pilarte JR, Sánchez MS. História da enfermagem: ciência do cuidar. Rev Gest Saúde. 2014;5(3):1181-96.

https://doi.org/10.18673/gs.v5i3.22708

3. Barbosa LBA, Motta ALC, Resck ZMR. Los paradigmas de la modernidad y posmodernidad y el proceso de cuidar en enfermería. Enferm Glob. 2015 [citado 10 set 2016];14(37):335-41.

Disponível em:

http://revistas.um.es/eglobal/article/viewFile/19 3101/169181

4. Schwartz GAD. A saúde na pós-modernidade. Rev Direito Danit. 2002;3(1):29-37.

https://doi.org/10.11606/issn.23169044.v3i1p29-37

5. Bauman Z. Vidas desperdiçadas. Rio de Janeiro: Zahar; 2005.

6. Zahar:.Zygmunt Bauman. Rio de Janeiro: Zahar; 2016 [citado 13 ago 2016]. Disponível em: http://www.zahar.com.br/autor/zygmuntbauman 
7. Bauman Z. Amor líquido: sobre a fragilidade dos laços humanos. Rio de Janeiro: Zahar; 2004.

8. Waldow VR. Cuidar: expressão humanizadora da enfermagem. 3a ed. Petrópolis: Vozes; 2010.

9. Martins JT, Galdino MJQ, Garanhani ML, Sammi KM, Trevisan GS. Humanização no processo de trabalho na percepção de enfermeiros de unidade de terapia intensiva. Cogitare Enferm. 2015;20(3):589-95. https://doi.org/10.5380/ce.v20i3.41521 10. Costa SRD, Castro EAB, Acioli S. Apoio de enfermagem ao autocuidado do cuidador familiar. Rev Enferm UERJ. 2015;23(2):197-202. https://doi.org/10.12957/reuerj.2015.16494 11. D'assunção CF, Santos ALD, Lino FA, Silveira EAA. A percepção da enfermagem sobre o relacionamento com os cuidadores dos portadores de Esquizofrenia: o olhar de um serviço de referência. Rev Enferm Centro-Oeste Min. 2016;1(6):2034-51.

https://doi.org/10.19175/recom.v0i0.709

12. Loures BP, Costa PHA, Ronzani TM. As redes sociais no cuidado aos usuários de drogas: revisão sistemática. Psicol Estud. 2016; 21(1):29-39. https://doi.org/10.4025/psicolestud.v21i1.28489 13. Zveiter M, Souza IEO. Solicitude constituindo o cuidado de enfermeiras obstétricas à mulherque-dá-à-luz-na-casa-de-parto. Esc Anna Nery. 2015;19(1):86-92. https://doi.org/10.5935/14148145.20150012

14. Bub MBC, Medrano C, Silva CDD, Wink S, Liss $P E$, Santos EKAD. A noção de cuidado de si mesmo e o conceito de autocuidado na enfermagem. Texto Contexto Enferm. 2006;15(n esp):152-7. https://doi.org/10.1590/S010407072006000500018

15. Martorell LB, Nascimento WF, Garrafa V. Redes sociais, privacidade, confidencialidade e ética: a exposição de imagens de pacientes no facebook. Interface (Botucatu). 2016;20(56):13-

23. https://doi.org/10.1590/1807-57622014.0902 16. Wolton D. Internet, e depois? Uma teoria crítica das novas mídias. 2a ed. Porto Alegre: Sulina; 2007.

17. Bauman Z. O mal-estar da pós-modernidade. Rio de Janeiro: Zahar; 1998.

18. Lopes RE, Silva AC, Nóbrega-Therrien SM. Formação reflexiva no ensino da Enfermagem: discussão à luz de Schön. Cad Pesqui.

2015;22(1):47-58.

https://doi.org/10.18764/2178-2229.v22.n1.p.47$\underline{58}$
19. Teixeira ER. A crítica e a sensibilidade no processo de cuidar na enfermagem. Esc Anna Nery. 2004 [citado 11 ago 2016];8(3):361-9. Disponível em:

http://revistaenfermagem.eean.edu.br/detalhe a rtigo.asp?id=976

20. Gabe J, Harley K, Calnan M. Healthcare choice: discourses, perceptions, experiences and practices. Curr Sociol. 2015;63(5):623-35. https://doi.org/10.1177/0011392115590061 21. Velho G. Individualismo e cultura: notas para uma antropologia da sociedade contemporânea. 8a ed. Rio de Janeiro: Zahar; 2008.

22. Sequeira, ARS. Interpretações locais sobre a malária e o discurso sobre os provedores tradicionais de cuidados de saúde no sul de Moçambique. Saúde Soc. 2016;25(2):392-407. https://doi.org/10.1590/S0104-12902016146036 23. Russo JA, Carrara SL. Sobre as ciências sociais na Saúde Coletiva: com especial referência à Antropologia. Physis. 2015;25(2):467-84. https://doi.org/10.1590/S010373312015000200008

24. Bailey DN. Mitigation of transcultural clinical barriers in a health and wellness program: $A$ transcultural caring approach for vulnerable migrant backstretch workers. Clin Nurs Stud. 2015;3(3):34-43.

https://doi.org/10.5430/cns.v3n3p34

25. Nicolli T, Gehlen M H, Ilha S, Diaz CMG, Machado KDFC, Nietsche EA. Teoria do autocuidado na desintoxicação química de gestantes em uso do crack: contribuições da enfermagem. Esc Anna Nery. 2015;19(3):417-23. https://doi.org/10.5935/1414-8145.20150055 26. Almeida LM, Aquino JM, Borba MC, Rosa MFS, Monteiro MAC. Promoção do autocuidado da pessoa em sofrimento psíquico. Rev Enf Dig Cuidados Promoção Saúde. 2015;1(2):66-70. https://doi.org/10.5935/2446-5682.20150012 27. Lake $S$, Rudge $T$, West S. Making meaning of nursing practices in acute care. J Organ Ethnogr. 2015;4(1):64-79. https://doi.org/10.1108/JOE-052014-0011

28. Bauman Z. Identidade: entrevista a Benedetto Vecchi. Rio de Janeiro: Zahar; 2005. 29. Bauman Z. Modernidade e ambivalência. Rio de Janeiro: Zahar; 1999.

30. González MA, Badía MC, Font CM. A Identidade do acadêmico de enfermagem: entre o ensino e a pesquisa Texto Contexto Enferm. 2014;23(2):241-49. https://doi.org/10.1590/0104$\underline{07072014001640013}$ 
31. Maissiat GS, Lautert L, Pai DD, Tavares JP. Contexto de trabalho, prazer e sofrimento na atenção básica em saúde. Rev Gaúcha Enferm. 2015;36(2):42-9. http://dx.doi.org/10.1590/19831447.2015.02.51128

32. Amaral JF, Ribeiro JP, da Paixão DX. Qualidade de vida no trabalho dos profissionais de enfermagem em ambiente hospitalar: uma revisão integrativa. Espaço Saúde. 2015 [citado 11 ago 2016];16(1):66-74. Disponível em: http://www.uel.br/revistas/uel/index.php/espaco parasaude/article/view/19158/pdf 64

33. Ferreira RG. Estresse do profissional de enfermagem no serviço noturno: uma questão de saúde. Rev Saúde Desenvol. 2016 [citado 11 ago 2016];7(4):147-65. Disponível em:

http://grupouninter.com.br/revistasaude/index.p $\mathrm{hp} /$ saudeDesenvolvimento/article/view/396/278 34. Morais MP, Martins JT, Galdino MJQ, Robazzi MLCC, Trevisan GS. Satisfação no trabalho de enfermeiros em um Hospital Universitário. Rev Enferm UFSM. 2016;6(1):1-9. https://doi.org/10.5902/2179769217766

Nota: Pesquisa proveniente de discussões e pesquisas do grupo Intervenções de Enfermagem no Processo SaúdeDoença (IENPSAD), realizada com fomento do Conselho Nacional de Desenvolvimento Científico e Tecnológico (CNPq).

Recebido: $25 / 10 / 2016$

Versão final: $14 / 08 / 2017$

Aprovado em: 14/08/2017

Endereço para Correspondência:

Rodovia Augusto Montenegro, Residencial João Coelho, no 11200 , bloco 13, apt 303

CEP: 66820-000 Belém/PA - Brasil

E-mail: juniorjorge_94@hotmail.com 